\title{
Associations between high callous-unemotional traits and quality of life across youths with non-conduct disorder diagnoses
}

\author{
Pierre C. M. Herpers ${ }^{1,2} \cdot$ Helen Klip ${ }^{1}$ Nanda N. J. Rommelse ${ }^{1,2}$. \\ Corina U. Greven ${ }^{1,3,4} \cdot$ Jan K. Buitelaar ${ }^{1,3}$
}

Received: 26 April 2015 / Accepted: 27 August 2015 / Published online: 11 September 2015

(C) The Author(s) 2015. This article is published with open access at Springerlink.com

\begin{abstract}
Research regarding callous-unemotional (CU) traits in non-conduct disorder (CD) diagnoses is sparse. We investigated the presence of high $\mathrm{CU}$ traits and their associations with quality of life (QoL) in a clinically referred sample of youths with non-CD diagnoses. Parents of 1018 children referred to a child and adolescent psychiatric clinic and rated their child's CU traits and QoL. Experienced clinicians derived DSM-IV-TR diagnoses based on systematic clinical evaluations of these children. High CU traits compared to low $\mathrm{CU}$ traits were present in $38.5 \%$ of the sample, and more often in boys than girls (69.4 vs. $30.6 \%, p=.004)$, and were associated with more police contacts $(12.2$ vs. $3.5 \%, p<.001)$. Logistic regression analyses revealed that those with diagnoses of autism spectrum disorder (odds ratio; $\mathrm{OR}=1.61 ; 95 \%$ CI 1.24-2.09; $p<.001)$ and disruptive behavior disorder not otherwise specified/oppositional defiant disorder $(\mathrm{OR}=4.98 ; 95 \%$
\end{abstract}

Electronic supplementary material The online version of this article (doi:10.1007/s00787-015-0766-5) contains supplementary material, which is available to authorized users.

Pierre C. M. Herpers

p.herpers@karakter.com

1 University Center, Karakter Child and Adolescent Psychiatry, Reinier Postlaan 12, 6525 GC Nijmegen, The Netherlands

2 Department of Psychiatry, Donders Institute for Brain, Cognition and Behaviour, Radboud University Medical Center, Nijmegen, The Netherlands

3 Department of Cognitive Neuroscience, Donders Institute for Brain, Cognition and Behaviour, Radboud University Medical Center, Nijmegen, The Netherlands

4 Institute of Psychiatry, Psychology \& Neuroscience, Medical Research Council Social, Genetic \& Developmental Psychiatry Centre, King's College London, London, UK
CI $2.93-8.64 ; p<.001)$, but not attention-deficit/hyperactivity disorder $(\mathrm{OR}=1.01 ; 95 \% \mathrm{CI} .79-1.31 ; p=.94)$, were more likely to have high than low CU traits. Those with anxiety/mood disorders were more likely to have low than high CU traits (OR $=.59 ; 95 \% \mathrm{CI} .42-82 ; p=.002)$. In all diagnostic groups, high $\mathrm{CU}$ compared to low $\mathrm{CU}$ traits were associated with significantly lower QoL, while controlling for gender, age, and comorbidity. As such, high CU traits significantly modify QoL in non-CD disorders.

Keywords Callous-unemotional traits · ADHD · ASD · Mood disorder · Conduct disorder · Quality of life

\section{Introduction}

Callous-unemotional (CU) traits are thought to represent the core component of psychopathy, and include symptoms such as lack of feeling guilty, lack of empathy, being very egocentric, showing callous use of others for one's own gain, and lacking normal emotionality, especially in showing a lack of anxiety [13]. CU traits were incorporated in the DSM-5 [2] as a specifier for conduct disorder (CD). The specifier consists of four criteria of which at least two should be met to index a more severe form of CD. CU traits in children with conduct problems (CP) have been reported to imply increased levels of aggressive behaviors, worse prognosis, and treatment refractoriness [14]. Increasingly, research shows neurobiological underpinnings of psychopathy, in which reduced amygdala responsiveness to distress cues results in reduced empathic response to distress of other individuals (as captured by the callous-unemotional component of psychopathy). In addition, dysfunction in the ventromedial prefrontal cortex and striatum results in deficient decision making and reinforcement learning (as 
captured by the impulsive-antisocial component of psychopathy; for a comprehensive review, see [5]).

The majority of research on CU traits has been conducted in youths with CP. However, little is known about the presence of $\mathrm{CU}$ traits in disorders other than $\mathrm{CD}$ and about their implications for severity of these disorders and functional adaptation [20,32]. In previous research, $\mathrm{CU}$ traits were not associated with quality of life (QoL) in a clinical sample of youths with CD [22]. Impairment in youths with CP showed either no [19, 22, 29, 30] or a positive $[15,25]$ relationship with $\mathrm{CU}$ traits. In community samples high CU traits were associated with more global impairment [10, 34, 43], not only in the CD subsample, but in the no CD/high CU subsample as well [34]. There are indications that impairment in the presence of attentiondeficit/hyperactivity disorder (ADHD) symptoms may be moderated by $\mathrm{CU}$ traits $[6,44]$. However, no studies reported yet on $\mathrm{QoL}$ in specific non-CD diagnoses.

Our cross-sectional study extends previous research, by examining associations between $\mathrm{CU}$ traits and non-CD diagnoses in a large clinical sample and by investigating relations between $\mathrm{CU}$ traits and QoL across non-CD disorders. We addressed the following questions: (1) what are the odds for scoring high on CU traits when being diagnosed having a psychiatric disorder other than CD?, (2) what is the relation between high $\mathrm{CU}$ traits and QoL in non-CD diagnoses?

\section{Method}

\section{Sample}

Data were used of a sample of 1833 juveniles (aged 6 and older) who were consecutively referred to Karakter, a child and adolescent psychiatric clinic in the Netherlands. We focused on data collected between July 2012 and May 2013. Services ranged from outpatient to high intensive mental healthcare, for patients with an estimated normal intelligence (IQ >70). Estimated intelligence is based on either clinical functioning (e.g., in case of good functioning in school) or by administering an intelligence test (i.e., predominantly the Wechsler Intelligence Scale for Children [45]). Clinical DSM-IV-TR [3] diagnoses were established by a multidisciplinary team based on information gathered by a child psychiatrist (developmental history, child observation, and psychiatric assessment), by a child psychologist, and review of clinical and prior records, including information available from school or other professional institutions involved with the child. Thus, a consensus diagnosis is assigned, which is seen as most reliable, compared to structured interviews when broad diagnostic categories are investigated [27]. In The Netherlands, severe CP are usually not treated within a psychiatric setting, but in juvenile welfare centers or juvenile penitentiary institutions. Hence, our clinic serves a specific population in which disruptive behavior disorders are only seen as a comorbid disorder and not as primary diagnosis.

Before the first appointment at the clinic, parents completed a digital intake questionnaire which assessed a range of variables, including age, gender, country of birth, number of police contacts of the child, education level of parents, and also included validated questionnaires such as the Kidscreen-27 [37] for measuring QoL. For this study, the Inventory of Callous-Unemotional traits (ICU) [12] was added to the intake questionnaire. Global functioning was rated by experienced child and adolescent psychiatrists using the Global Assessment of Functioning Scale according the DSM-IV-TR [3] criteria. Scores above 60 reflect no or minor functional impairment. This study was approved by the Institutional Review Board.

Participants whose parents gave informed consent ( $n=1190)$ were included in this study. However, at the time of statistical analysis, data regarding DSM-IV-TR diagnosis were missing for $n=154$, in which additional diagnostic information was being gathered and consensus was not reached yet. Furthermore, 7 juveniles were excluded because of invalid entry of Kidscreen scores (described below), 6 juveniles because of age above 18 years, and 5 juveniles because they were diagnosed with CD. This resulted in a sample of 1018 youths.

\section{Measures}

Parents rated their child on callous-unemotional traits using the Dutch translation of the 24-item ICU, which assesses callous-unemotional personality traits [39], rated on a 4-point Likert scale ranging from $0=$ does not apply at all to $3=$ applies very well. Internal consistency of the Dutch ICU was shown to be good $[8,39]$. In our study Cronbach's Alpha was also good (.89). Concurrent validity between the ICU and psychopathy scales is acceptable $\left(r^{2}=.45-.68\right)$ between ICU and antisocial process screening device (APSD), and childhood psychopathy scale (CPS) $[24,39]$. Mean total score for the parent report ICU in a community sample (aged $11-16$ years, $n=174$ ) was previously found to be 22.28 ( $\mathrm{SD}=9.30 ;$ [26]).

Quality of life was measured by parent ratings on the Kidscreen-27 [36]. The Kidscreen-27 assesses general well-being and subjective health in youths, and contains 27 questions related to five dimensions (Physical Well-being, Psychological Well-being, Autonomy and Parent Relations, Social Support and Peers, School Environment), as well as giving rise to a total QoL score. Each item is being rated on a 5-point Likert scale from $1=$ not at all/never to $5=$ totally/always. Thus, low Kidscreen scores reflect 
lower QoL. Previous studies showed a positive relationship between severity of mental health problems in youths and QoL as measured by the Kidscreen-27 [9, 46]. The questionnaire has been tested in multiple countries and is validated in Dutch. Internal consistencies (Cronbach's Alpha) were reported to be $>0.75$ [36]. In our study, Cronbach's Alpha for the total Kidscreen-27 was .90.

\section{Analyses}

IBM SPSS Statistics 21 was used for statistical analyses. The continuous data on the ICU were broken down into a high and a low scoring group. Although no widely accepted cut-off has been accepted yet, we used a cut-off score of 32 on the ICU (i.e., score $<32=$ low $\mathrm{CU}$; score $\geq 32=$ high $\mathrm{CU})$. This is in line with previous studies [21, 41], in which youths with similar age, with $\mathrm{CP}$, and also with autism spectrum disorder (ASD) was included. In our sample, the mean ICU score was 28.75 ( $\mathrm{SD}=11.21)$, which is similar to the mentioned studies. We made use of five diagnostic categories: ADHD, ASD, anxiety/mood, disruptive behavior disorder not otherwise specified (DBD-NOS)/ODD, and other diagnoses (see also Table S1, available online). Information on comorbidity is given in Table S2 (available online). Bivariate correlations are shown in Table S3 (available online). Diagnostic groups with high versus low $\mathrm{CU}$ traits were compared on sample descriptives using $\chi^{2}$ tests. To study the associations between diagnosis and presence of high CU traits, logistic regression analyses were performed entering diagnosis as dependent dichotomous variable and high/low ICU score as independent categorical variable. We repeated these analyses including age and gender as covariates. To examine whether high CU traits were linked to QoL, $t$ tests were performed to analyze the relationship between the dichotomous ICU scores and continuous Kidscreen data for the total sample and for each diagnostic group. Second we performed hierarchical multiple linear regression analyses predicting Kidscreen-27 scores (continuous variable) from age, gender (entered in step 1), and the dichotomous ICU variable (entered in step 2) for each diagnostic group. We have rerun analyses with exclusion of those participants whose IQ level was estimated being below 85 .

To test the robustness of our findings versus the chosen cut-off of 32, analyses were rerun with slightly higher or lower cut-offs (i.e., ICU $\geq 28$ and ICU $\geq 35$ ) in addition to a hierarchical multiple linear regression with the continuous ICU score. We ran primary analyses on groups including comorbidities to make use of the full sample; however, we also reran analyses on participants free of any comorbidity to examine potential confounding by comorbidity. We also ran sensitivity analyses to test the robustness of results. First, we examined whether results were similar for continuous ICU scores. Second, we examined the role of IQ by excluding those with an estimated IQ below 85 . Third, we examined the role of stressful life events, measured as binary variable (yes/no), as reported by parents.

\section{Results}

\section{Descriptive results of the study sample by high and low CU traits}

The characteristics of the total sample, and separately for youths with high versus low $\mathrm{CU}$ traits are described in Table 1 . The high scoring group (i.e., ICU total score $\geq 32$ ) consisted of 392 participants, and the low scoring group of 626 participants. Mean ICU score for the high CU group was 40.26 ( $\mathrm{SD}=6.83)$. Mean ICU score for the low $\mathrm{CU}$ group was $21.54(\mathrm{SD}=6.32)$. Children scoring high on $\mathrm{CU}$ traits were more often male than female (69.4 vs. $30.6 \%$, $p=.004)$. Age, living in a larger city $(\geq 100,000$ inhabitants), and education level of the parent showed no significant correlations with $\mathrm{CU}$ traits. In addition, we found that those with high CU traits had lower Global Assessment of Functioning (GAF) scores $(p=.001)$ and more police contacts $(12.2$ vs. $3.5 \%, p<.001)$ than those scoring low on CU traits.

\section{Odd ratios for scoring high on $\mathrm{CU}$ traits in non-CD youths with psychopathology}

Of the total sample, $38.5 \%$ scored high on CU traits. In Table 2 the mean ICU scores per diagnosis are shown. Diagnoses of ASD (odd ratio; OR $=1.61 ; 95 \%$ CI 1.24 $2.09 ; p<.001)$ and DBD-NOS/ODD (OR $=4.98 ; 95 \%$ CI $2.93-8.64 ; p<.001)$, but not ADHD (OR $=1.01 ; 95 \%$ CI .79-1.31; $p=.94)$, were more often associated with the presence of high than low CU traits. Anxiety/mood disorders were more often associated with low than with high $\mathrm{CU}$ traits $(\mathrm{OR}=.59 ; 95 \% \mathrm{CI} .42-82 ; p=.002)$. For the ADHD and the other diagnoses groups, the OR was not significantly elevated. Entering age and gender into the model, for all diagnostic groups, the ORs were similar in magnitude and remained significant for ASD, DBD-NOS/ ODD, and anxiety/mood disorders.

\section{High CU traits and their relation to QoL in non-CD youths with psychopathology}

The Kidscreen analyses for the total sample showed that Kidscreen scores in the high CU group were significantly lower than those in the low CU group (91.1 vs. 98.7, $p<.001$; see Fig. 1). Similar findings emerged for all specific diagnostic groups: the high CU group showed lower 
Table 1 Characteristics of the study population, for the total group and for the ICU groups $(N=1018)$

Table 2 Associations between diagnosis and risk for $\mathrm{ICU} \geq 32$ expressed as odds ratio, and prevalence of high CU scores

\begin{tabular}{|c|c|c|c|c|c|c|c|}
\hline & \multirow{2}{*}{\multicolumn{2}{|c|}{$\begin{array}{l}\text { Total group } \\
(n=1018)\end{array}$}} & \multicolumn{4}{|l|}{ ICU } & \multirow[t]{3}{*}{$p$ value } \\
\hline & & & \multicolumn{2}{|c|}{$\begin{array}{l}\text { ICU score }<32 \\
(n=626)\end{array}$} & \multicolumn{2}{|c|}{$\begin{array}{l}\text { ICU score } \geq 32 \\
(n=392)\end{array}$} & \\
\hline & $n$ & $\%$ & $n$ & $\%$ & $n$ & $\%$ & \\
\hline \multicolumn{8}{|l|}{ Age (years) } \\
\hline $6 \leq 11$ & 572 & 56.2 & 366 & 58.5 & 206 & 52.6 & \multirow[t]{3}{*}{.11} \\
\hline $12 \leq 15$ & 330 & 32.4 & 188 & 30.0 & 142 & 36.2 & \\
\hline $16 \leq 18$ & 116 & 11.4 & 72 & 11.5 & 44 & 11.2 & \\
\hline \multicolumn{8}{|l|}{ Gender } \\
\hline Male & 651 & 63.9 & 379 & 60.5 & 272 & 69.4 & \multirow[t]{2}{*}{.004} \\
\hline Female & 367 & 36.1 & 247 & 39.5 & 120 & 30.6 & \\
\hline \multicolumn{8}{|l|}{ Education level of child } \\
\hline Primary education & 404 & 42.0 & 275 & 46.4 & 129 & 35.0 & \multirow[t]{5}{*}{.001} \\
\hline Special needs education & 177 & 18.4 & 100 & 16.9 & 77 & 20.9 & \\
\hline $\begin{array}{l}\text { Special needs secondary educa- } \\
\text { tion }\end{array}$ & 108 & 11.2 & 57 & 9.6 & 51 & 13.8 & \\
\hline $\begin{array}{l}\text { Preparatory middle-level voca- } \\
\text { tional education }\end{array}$ & 142 & 14.8 & 74 & 12.5 & 68 & 18.4 & \\
\hline $\begin{array}{l}\text { Higher vocational education/pre- } \\
\text { paratory university education }\end{array}$ & 131 & 13.6 & 87 & 14.7 & 44 & 11.9 & \\
\hline \multicolumn{8}{|l|}{ City $\geq 100.000$} \\
\hline Yes & 308 & 30.4 & 190 & 30.4 & 118 & 30.3 & .97 \\
\hline \multicolumn{8}{|l|}{ Education level of parent } \\
\hline Lower & 134 & 13.8 & 79 & 13.2 & 55 & 14.9 & \multirow[t]{3}{*}{.75} \\
\hline Middle & 415 & 42.9 & 259 & 43.2 & 156 & 42.3 & \\
\hline Higher & 419 & 43.3 & 261 & 43.6 & 158 & 42.8 & \\
\hline \multicolumn{8}{|l|}{ GAF score } \\
\hline $1 \leq 40$ & 113 & 11.1 & 58 & 9.3 & 55 & 14.0 & \multirow[t]{3}{*}{$<.001$} \\
\hline $41 \leq 60$ & 832 & 81.8 & 508 & 81.3 & 324 & 82.7 & \\
\hline $61 \leq 100$ & 72 & 7.1 & 59 & 9.4 & 13 & 3.3 & \\
\hline \multicolumn{8}{|l|}{ Police contacts } \\
\hline Yes & 70 & 7.2 & 22 & 31.4 & 48 & 68.6 & $<.001$ \\
\hline \multicolumn{8}{|l|}{ Stressful life events } \\
\hline Yes & 563 & 59.3 & 334 & 59.3 & 229 & 40.7 & $<.05$ \\
\hline
\end{tabular}

$G A F$ global assessment of functioning

${ }^{\text {a }} \chi^{2}$ test comparing ICU score $<32$ vs. ICU score $\geq 32$ on study population characteristics

\begin{tabular}{|c|c|c|c|c|c|c|c|c|c|c|}
\hline \multirow[t]{2}{*}{ Diagnosis $^{a}$} & \multicolumn{2}{|c|}{ ICU score } & \multirow[t]{2}{*}{ OR } & \multirow[t]{2}{*}{$95 \% \mathrm{CI}$} & \multirow[t]{2}{*}{$\mathrm{OR}_{\text {adj }}$} & \multirow[t]{2}{*}{$95 \% \mathrm{CI}_{\mathrm{adj}}$} & \multicolumn{2}{|c|}{ ICU $<32$} & \multicolumn{2}{|c|}{$\mathrm{ICU} \geq 32$} \\
\hline & $M$ & SD & & & & & $n$ & $\%$ & $n$ & $\%$ \\
\hline ADHD & 28.7 & 11.0 & 1.02 & $.79-1.31$ & 1.01 & $.79-1.31$ & 274 & 61.3 & 173 & 38.7 \\
\hline ASD & 30.6 & 10.9 & $1.68 * *$ & $1.30-2.17$ & $1.61 * *$ & $1.24-2.09$ & 238 & 54.5 & 199 & 45.5 \\
\hline Anxiety/mood & 26.2 & 11.5 & $.61 *$ & $.45-0.83$ & $.59 *$ & $.43-.82$ & 167 & 70.2 & 71 & 29.8 \\
\hline DBD-NOS/ODD & 37.6 & 11.7 & $5.05 * *$ & $2.98-8.56$ & $4.98 * *$ & $2.93-8.47$ & 20 & 26.3 & 56 & 73.7 \\
\hline Other diagnoses & 29.2 & 11.6 & 1.08 & $.84-1.40$ & 1.11 & $.86-1.44$ & 256 & 60.4 & 168 & 39.6 \\
\hline Total group & 28.8 & 11.2 & & & & & 626 & 61.5 & 392 & 38.5 \\
\hline
\end{tabular}

adj adjusted for age and gender, $O R$ odds ratio, $I C U$ inventory of callous-unemotional traits, $95 \% C I 95 \%$ confidence interval, $A D H D$ attention-deficit/hyperactivity disorder, ASD autism spectrum disorder, Anxiety/mood either anxiety or mood disorder, $D B D-N O S / O D D$ either disruptive behavior disorder not otherwise specified or oppositional defiant disorder, Other Diagnoses are listed in table S1

$* p=.002 ; * * p<.001$

${ }^{a}$ With any or without comorbidity 
Fig. 1 Mean Kidscreen scores and standard error of the mean (SEM) by diagnosis, $* p<.01$, $* * p<.001, I C U$ inventory of callous-unemotional traits, $A D H D$ attention-deficit/hyperactivity disorder, ASD autism spectrum disorder, Anxiety/ mood either anxiety or mood disorder, $D B D-N O S / O D D$ either disruptive behavior disorder not otherwise specified or oppositional defiant disorder, Other Diagnoses are listed in table $\mathrm{S} 1$. Diagnoses are with any and without comorbidity

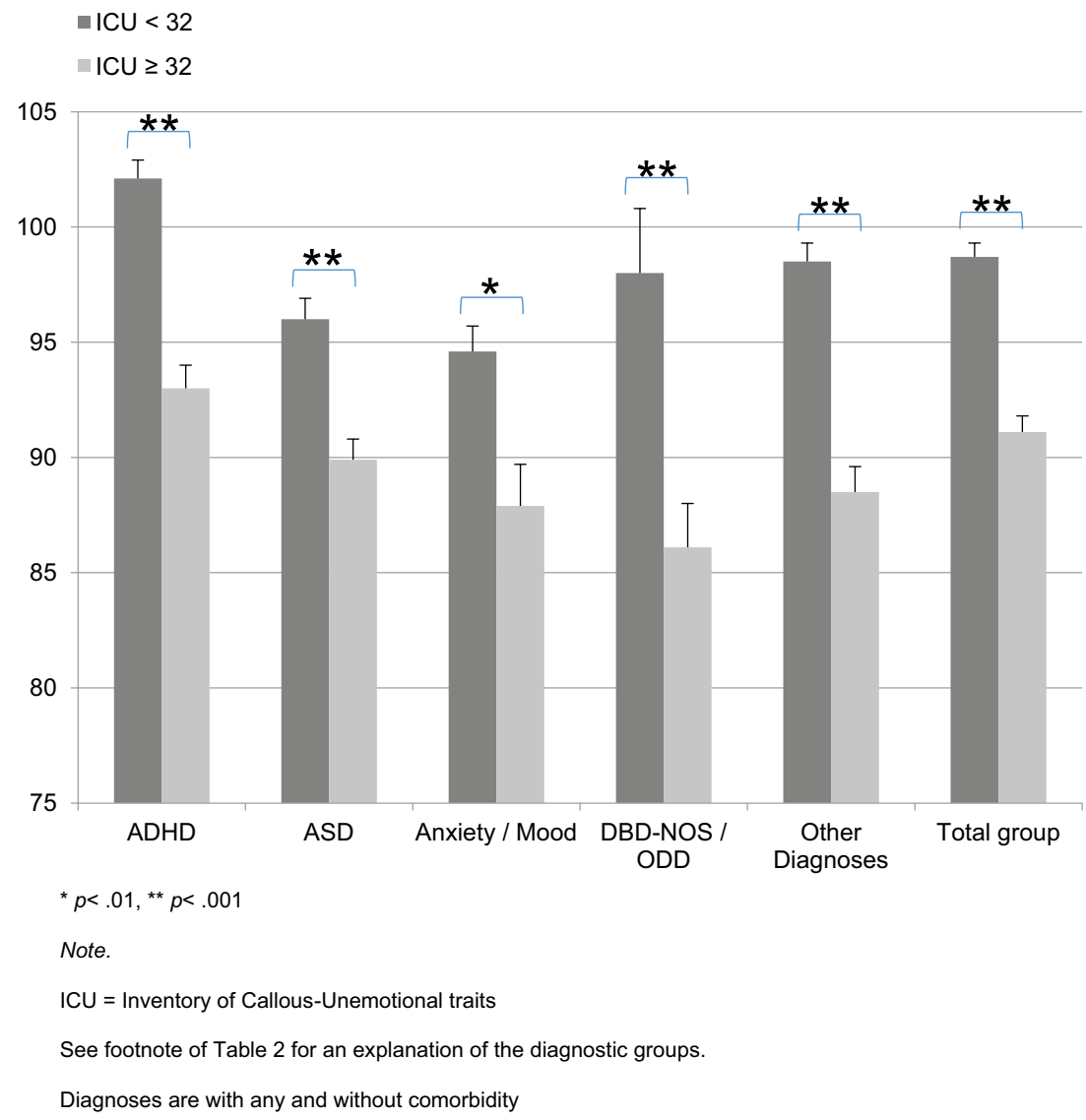

Table 3 Hierarchical multiple linear regression analyses predicting Kidscreen scores from age, gender, and ICU by diagnosis

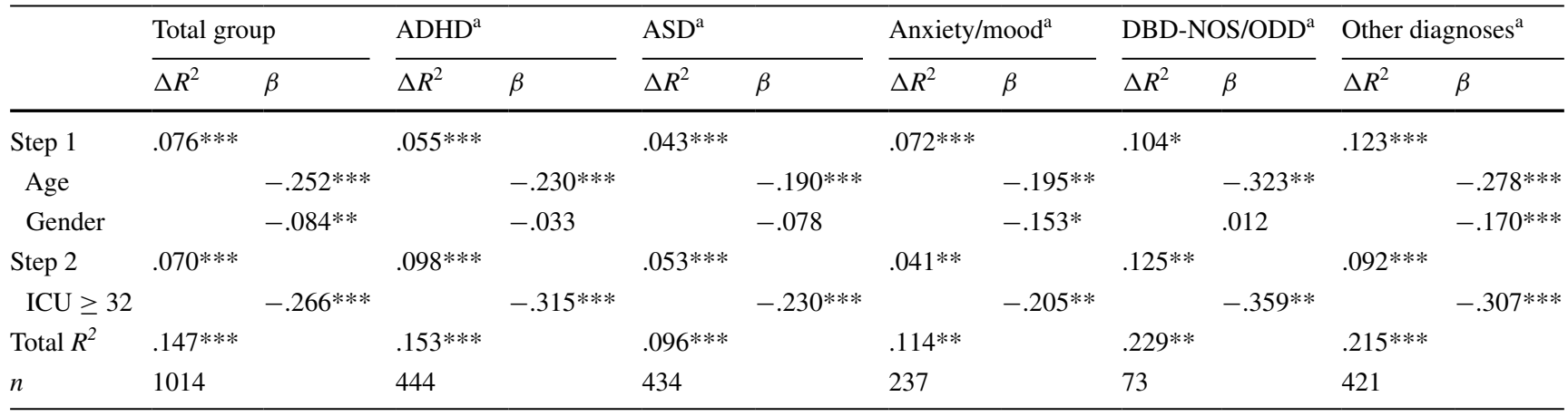

$\beta$ standardized regression coefficient, $I C U$ inventory of callous-unemotional traits, $A D H D$ attention-deficit/hyperactivity disorder, $A S D$ autism spectrum disorder, Anxiety/mood either anxiety or mood disorder, $D B D$-NOS/ODD either disruptive behavior disorder not otherwise specified or oppositional defiant disorder, Other Diagnoses are listed in table S1

$* p<.05, * * p<.01 * * * p<.001$

${ }^{\text {a }}$ With any or without comorbidity

Kidscreen scores for ADHD (92.9 vs. 102.1, $p<.001)$, ASD (89.9 vs. $95.9, p<.001)$, anxiety/mood $(87.9$ vs. 94.6 , $p=.002)$, DBD-NOS/ODD (86.1 vs. $98.3, p<0.001)$, and other diagnoses (91.1 vs. $98.5, p<.001)$.

High ICU scores predicted Kidscreen scores $\left(\beta_{\text {Total }}\right.$ group $=-.266, p<.001 ; \beta=$ standardized regression coefficient), explaining $4-13 \%$ of the variance in Kidscreen scores beyond effects of age and gender (see Table 3). Collinearity statistics showed that the results for the variance inflation factor in the linear regression analyses (taken the analyses with and those without comorbidity together) ranged between 1.001 and 1.126, while tolerance ranged between .888 and .999 . Thus, there seems to be no collinearity. Post hoc analyses entering age, gender, education 
level of parents, police contacts, and DBD-NOS/ODD in step 1 of the regression and ICU scores in step 2 found that education level of parents and the police contacts did not contribute significantly to the model, while DBD-NOS/ ODD contributed significantly in the total group $(\beta=.061$, $p<.05)$, in the $\operatorname{ASD}(\beta=.133, p<.01)$, and in the anxiety/ mood disorders group $(\beta=.131, p<.05)$. However, results for $\mathrm{CU}$ traits stayed similar.

\section{Sensitivity analyses}

Bivariate correlations with continuously distributed ICU scores (Table S3) yielded a significant inverse relationship between the continuous ICU and Kidscreen-27 scores $(r=-.32, p<.001)$, and continuous ICU and GAF scores $(r=-.16, p<.001)$. Regression analyses yielded similar results when we entered ICU continuous scores into the model (Table S5, available online) or when using slightly higher or lower cut-off scores (i.e., ICU $\geq 28$ and ICU $\geq 35$ ). In the 'no co-morbidity' analyses, most results stayed in the same direction. Nevertheless, the group with ADHD only showed a decrease of the likelihood of scoring high on CU traits, while findings for the other groups were in the same direction as in the primary analyses including comorbidities (see Table S4, available online). Results of the regression analyses no longer reached significance in the anxiety/mood and the DBD-NOS/ODD group (see Tables S6 and S7, available online). Rerunning our analyses excluding those participants with an estimated IQ below 85, overall, results stayed similar and significant for the ORs. For the regression analyses, results stayed in the same direction. Finally, $\chi^{2}$ analyses showed stressful life events to be significantly more present in youths with high $\mathrm{CU}$ traits. However, bivariate correlations did show only small, non-significant relationships. Adding stressful life events to the first step of our regression analyses did not alter results regarding the ICU, except in the other diagnoses group, in which significance of the predictive value of the ICU was lost.

\section{Discussion}

This study investigated whether CU traits should be seen as a cross disorder phenomenon that also occurs outside $\mathrm{CD}$, and whether high $\mathrm{CU}$ traits outside $\mathrm{CD}$ affect functioning in important domains as reflected in a measure of QoL. In our large clinical sample, the odds for high CU traits were found to be significantly increased in ASD and DBD-NOS/ODD, while the odds for high CU traits were found to be significantly decreased in anxiety/mood disorders. For ADHD and other diagnoses, the odds for high CU traits were not significantly increased. A new and important finding is that, in all diagnostic groups, high CU traits were associated with lower QoL, and explained a significant proportion of variance (4-13\%) in QoL beyond effects of age and gender. In contrast, education level of child or parents and the police contacts were unrelated to QoL.

These findings support and extend earlier studies reporting on CU traits being present outside CD [40] and on the negative impact of $\mathrm{CU}$ traits across disorders [7]. In contrast to previous research in youths with $\mathrm{CP}$ (which refers to a broader concept than our DBD-NOS/ODD diagnosis), we found QoL to be significantly decreased in the high CU group compared to the low CU group. Our DBD-NOS/ ODD only sample was small, however, findings remained in the same direction when controlling for comorbidity. Thus, our results underscore the importance of considering CU traits as a specifier for ODD as well [20]. Nevertheless, as only one scale and only one source of information has been used to detect $\mathrm{CU}$ traits, we need to keep in mind that parents might rate 'Has your child been able to pay attention' (Kidscreen-27 item) similar as being 'concerned about schoolwork' (ICU item).

In the ADHD group, our findings contrast with previous results showing that $\mathrm{CU}$ traits moderate functional impairment in those with low and moderate levels of ADHD symptoms [6]. In our sample, $\mathrm{CU}$ traits were related to QoL in those with a diagnosis of ADHD, all of whom had at least moderate or high levels of ADHD symptoms. This is an important finding because $\mathrm{CU}$ traits may moderate treatment response in ADHD as well. Effects of behavioral therapy were found to be less in the presence of high CU traits compared to those with low CU traits [16-18, 42], which might be related to the component of punishment in the treatment program [31]. Methylphenidate was found to show a positive effect on $\mathrm{CU}$ traits [4] and on $\mathrm{CP}$ [42]. However, it is unclear whether the effect of CU traits in these ADHD samples was confounded by comorbidity with ODD or CD. Therefore, we controlled for comorbid DBD-NOS/ODD and were able to show CU traits having incremental value in predicting $\mathrm{QoL}$ in youths with ADHD, over and beyond CP. It is important to note that this effect existed independently of the finding that on average there was no increased OR for CU traits in ADHD. Thus, $\mathrm{CU}$ traits may be an independent predictor of treatment response regardless of diagnosis.

Previous studies showed that high scores on CU traits in youths with ASD may, at least in part, reflect theory of mind (ToM) deficits due to impaired empathic response to distress cues [38], cognitive empathy deficits [21, 41], and significantly decreased medial prefrontal cortex responses during ToM tasks in youths with ASD compared to youths with $\mathrm{CP}$ and high CU traits, and typically developing youths [33]. Thus, high CU traits in ASD may be due to different underlying cognitive and brain mechanisms than 
high CU traits in CD. As we found a significantly increased OR for CU traits in ASD in this clinical sample, and high CU traits negatively impacted upon QoL, it is important to further unravel the relationship between $\mathrm{CU}$ traits and ASD.

This study confirmed previous studies that found a negative relationship between anxiety and CU traits (for a review, see e.g., [14]). The relationship between high CU traits and mood disorders has been investigated scarcely (see e.g., [20]). We found high CU traits within anxiety/ mood disorders to be related to significantly lower QoL. In this diagnostic group, this effect existed independently of the finding that on average there was a decreased OR for CU traits. However, when controlling for comorbidity, this effect disappeared, which might be due to the relative small number of participants in the high CU group (9 versus 39 in the low $\mathrm{CU}$ group). Also important to note is the fact that it is unknown whether $\mathrm{CU}$ traits in anxiety/mood disorders represent the same underlying construct as in youths with CP. Parents might, for example, be rating anhedonia rather than the lack of emotion, or social avoidance rather than hiding one's emotions. Further investigation of our finding is therefore needed in either anxiety and mood disorder only groups, as well as further research into the prognosis and treatment results of high CU traits in the presence of anxiety/mood disorders.

The main strength of this study was that it focused on the relation between CU traits and QoL in clinically established non-CD diagnoses in a large psychiatric outpatient sample. However, an important limitation is the lack of control groups, such as either (a large group of) youths with disruptive behavior disorders and normal controls. A potential limitation is the fact that there is no established cut-off score for the ICU. Although it still is difficult to define which is the best way to establish cut-off scores regarding the ICU [23], our results give important information about the distribution of high $\mathrm{CU}$ traits across non-CD disorders. Furthermore, the fact that we relied on parentreported assessment of $\mathrm{CU}$ traits and of QoL may mean that shared method variance may have inflated correlations between these two variables. However, regarding the individuals items, there is virtually no overlap, which also emerged from collinearity analyses. Nevertheless, future studies might adopt a more comprehensive multi-informant multi-measure approach to assess $\mathrm{CU}$ traits, to be able to address issues of potential informant and instrument bias. Also, future research might benefit a structured interview to establish CU traits, such as the Clinical Assessment of Prosocial Emotions [11] which provides DSM diagnoses of $\mathrm{CU}$ traits. However, this is a clinician-rated measure and published only recently, and not available at time of our data collection. However, its value has to be established yet. Similarly, much of the analyses depend on clinical diagnoses that were not made with a structured and wellestablished clinical interview (e.g., the K-SADS). Nevertheless, our diagnostic procedures were similar to those to reach best estimate clinical diagnoses and as such, thought to be more reliable than the use of structured interviews only [27]. Not having addressed intelligence as a covariate in our analyses is also a limitation. As we did not gather information regarding intelligence in a standardized way, we applied a broad definition of intelligence in terms of identifying individuals with borderline intellectual functioning (IQ below 85). Although our results stayed similar when excluding those with an estimated IQ below 85, previous findings about the relationship between psychopathic traits and intelligence in conduct disorder have been contrasting [1]. Therefore, it could be noteworthy to specifically examine the impact of IQ on CU traits in non-CD disorders. Also, we did not investigate the temporal relation between CU traits and stressful life events. Given the discussion regarding secondary psychopathy in which traumatization is seen as possible moderating CU traits [28], it may be important to investigate whether traumatized children show CU behavior due to their traumatization ("emotional numbness'), rather than having a truly underlying high CU phenotype. As we did not gather longitudinal data, we have no information that addresses a developmental perspective of CU traits, and as such its possible malleability through time [35].

Several unanswered questions remain for future research. One such question is: what is the mechanism through which high $\mathrm{CU}$ traits affect QoL in non-CD disorders? The relationship between $\mathrm{CU}$ traits and non-CD disorders is poorly understood. It is unknown how peers perceive youths with high CU traits, and there may be other ways in which social relationships are compromised. Also we do not know whether there is equifinality or multifinality in the causes of high CU traits in non-CD disorders compared to those causes in $\mathrm{CD}$. High $\mathrm{CU}$ traits may be related to decreased problem solving skills and thus predispose to less help-seeking behavior or being less help receptive and thus to decreased QoL. Although age was not found to be a significant moderator or covariate, it remains unclear whether $\mathrm{CU}$ traits in these diagnostic groups may have different meanings at different ages. As such, many issues for further research remain.

\section{Conclusion}

This study showed that increased CU traits are not limited to $\mathrm{CD}$ only. Instead, $\mathrm{CU}$ traits occur as a cross disorder phenomenon, and are related to low QoL even in disorders that are not per se associated with an increased risk for high CU traits. Our data suggest clinicians should pay 
attention to $\mathrm{CU}$ traits also in non-CD disorders. Further research is needed into the consequences of high $\mathrm{CU}$ traits for response to treatment, prognosis, and course of these non-CD disorders.

Acknowledgments This study was supported by Karakter. The study is further supported by the European Union 7th Framework programs AGGRESSOTYPE (602805) and MATRICS (603016) and by a NWO Brain \& Cognition Grant (056-24-011). We are grateful to participating families.

\section{Compliance with Ethical Standards}

Conflict of interest In the past 3 years, Buitelaar has been a consultant to/member of advisory board of/and/or speaker for Janssen Cilag BV, Eli Lilly, Bristol-Myer Squibb, Shering Plough, UCB, Shire, Novartis, and Servier. He is not an employee of any of these companies, and not a stock shareholder of any of these companies. He has no other financial or material support, including expert testimony, patents, and royalties. Drs. Herpers, Klip, Rommelse, and Greven have no biomedical, financial interests, or potential conflicts of interest.

Ethical Approval This study has been approved by the Institutional Review Board and has therefore been performed in accordance with the ethical standards laid down in the 1964 Declaration of Helsinki and its later amendments. All persons gave their informed consent prior to their inclusion in the study.

Open Access This article is distributed under the terms of the Creative Commons Attribution 4.0 International License (http://creativecommons.org/licenses/by/4.0/), which permits unrestricted use, distribution, and reproduction in any medium, provided you give appropriate credit to the original author(s) and the source, provide a link to the Creative Commons license, and indicate if changes were made.

\section{References}

1. Allen JL, Briskman J, Humayun S, Dadds MR, Scott S (2013) Heartless and cunning? Intelligence in adolescents with antisocial behavior and psychopathic traits. Psychiatry Res 210:1147-1153

2. American Psychiatric Association (2013) Diagnostic and statistical manual of mental disorders, 5th edn. American Psychiatric Association, Washington, D.C

3. American Psychiatric Association (2000) Diagnostic and statistical manual of mental disorders, 4th edn. American Psychiatric Association, Washington, D.C. Text Revision

4. Blader JC, Pliszka SR, Kafantaris V, Foley CA, Crowell JA, Carlson GA, Sauder CL, Margulies DM, Sinha C, Sverd J, Matthews TL, Bailey BY, Daviss WB (2013) Callous-unemotional traits, proactive aggression, and treatment outcomes of aggressive children with attention-deficit/hyperactivity disorder. J Am Acad Child Adolesc Psychiatry 52:1281-1293

5. Blair RJR (2013) The neurobiology of psychopathic traits in youths. Nat Rev Neurosci 14:786-799

6. Brammer WA, Lee SS (2012) Impairment in children with and without ADHD: contributions from oppositional defiant disorder and callous-unemotional traits. J Atten Disord 16:535-543

7. Dadds MR, Cauchi AJ, Wimalaweera S, Hawes DJ, Brennan J (2012) Outcomes, moderators, and mediators of empathic-emotion recognition training for complex conduct problems in childhood. Psychiatry Res 199:201-207

8. Decuyper M, De Clercq B, De Bolle M, De Fruyt F (2009) Validation of FFM PD counts for screening personality pathology and psychopathy in adolescence. J Pers Disord 23:587-605

9. Dey M, Mohler-Kuo M, Landolt MA (2012) Health-related quality of life among children with mental health problems: a population-based approach. Health Qual Life Outcomes 10:73

10. Ezpeleta L, de la Osa N, Granero R, Penelo E, Domenech JM (2013) Inventory of callous-unemotional traits in a community sample of preschoolers. J Clin Child Adolesc Psychol 42:91-105

11. Frick PJ (2013) Clinical Assessment of Prosocial Emotions: Version 1.1 (CAPE 1.1). University of New Orleans

12. Frick PJ (2004) The Inventory of Callous-unemotional Traits. Unpublished work

13. Frick PJ, Ellis M (1999) Callous-unemotional traits and subtypes of conduct disorder. Clin Child Fam Psychol Rev 2:149-168

14. Frick PJ, Ray JV, Thornton LC, Kahn RE (2014) Can callousunemotional traits enhance the understanding, diagnosis, and treatment of serious conduct problems in children and adolescents? A comprehensive review. Psychol Bull 140:1-57

15. Graziano PA, Ros R, Haas S, Hart K, Slavec J, Waschbusch D, Garcia A (2015) Assessing callous-unemotional traits in preschool children with disruptive behavior problems using peer reports. J Clin Child Adolesc Psychol. doi:10.1080/15374416.2 014.971460

16. Haas SM, Waschbusch DA, Pelham WE Jr, King S, Andrade BF, Carrey NJ (2011) Treatment response in CP/ADHD children with callous/unemotional traits. J Abnorm Child Psychol 39:541-552

17. Hawes DJ, Dadds MR (2007) Stability and malleability of callous-unemotional traits during treatment for childhood conduct problems. J Clin Child Adolesc Psychol 36:347-355

18. Hawes DJ, Dadds MR (2005) The treatment of conduct problems in children with callous-unemotional traits. J Consult Clin Psychol 73:737-741

19. Hemphälä M, Hodgins S (2014) Do psychopathic traits assessed in mid-adolescence predict mental health, psychosocial, and antisocial, including criminal outcomes, over the subsequent 5 years? Can J Psychiatry 59:40-49

20. Herpers PCM, Rommelse NNJ, Bons DMA, Buitelaar JK, Scheepers FE (2012) Callous-unemotional traits as a crossdisorders construct. Soc Psychiatry Psychiatr Epidemiol 47:2045-2064

21. Jones AP, Happé FG, Gilbert F, Burnett S, Viding E (2010) Feeling, caring, knowing: different types of empathy deficit in boys with psychopathic tendencies and autism spectrum disorder. J Child Psychol Psychiatry 51:1188-1197

22. Kahn RE, Frick PJ, Youngstrom E, Findling RL, Youngstrom JK (2012) The effects of including a callous-unemotional specifier for the diagnosis of conduct disorder. J Child Psychol Psychiatry 53:271-282

23. Kimonis ER, Fanti KA, Frick PJ, Moffitt TE, Essau C, Bijttebier P, Marsee MA (2014) Using self-reported callous-unemotional traits to cross-nationally assess the DSM-5 'With Limited Prosocial Emotions' specifier. J Child Psychol Psychiatry. doi:10.1111/ jcpp. 12357

24. Kimonis ER, Frick PJ, Skeem JL, Marsee MA, Cruise K, Munoz LC, Aucoin KJ, Morris AS (2008) Assessing callous-unemotional traits in adolescent offenders: validation of the inventory of callous-unemotional traits. Int J Law Psychiatry 31:241-252

25. Kolko DJ, Pardini DA (2010) ODD dimensions, ADHD, and callous-unemotional traits as predictors of treatment response in children with disruptive behavior disorders. J Abnorm Psychol 119:713-725 
26. Latzman RD, Lilienfeld SO, Latzman NE, Clark LA (2013) Exploring callous and unemotional traits in youth via general personality traits: an eye toward DSM-5. Personal Disord 4:191-202

27. Leckman JF, Sholomkas D, Thompson WD, Belanger A, Weissman MM (1982) Best estimate of a lifetime psychiatric diagnosis: a methodological study. Arch Gen Psychiatry 39:879-883

28. Lee Z, Salekin RT, Iselin AM (2010) Psychopathic traits in youth: is there evidence for primary and secondary subtypes? $\mathrm{J}$ Abnorm Child Psychol 38:381-393

29. Masi G, Manfredi A, Milone A, Muratori P, Polidori L, Ruglioni L, Muratori F (2011) Predictors of nonresponse to psychosocial treatment in children and adolescents with disruptive behavior disorders. J Child Adolesc Psychopharmacol 21:51-55

30. Masi G, Muratori P, Manfredi A, Lenzi F, Polidori L, Ruglioni L, Muratori F, Milone A (2013) Response to treatments in youth with disruptive behavior disorders. Compr Psychiatry 54:1009-1015

31. Miller NV, Haas SM, Waschbusch DA, Willoughby MT, Helseth SA, Crum KI, Coles EK, Pelham WE Jr (2014) Behavior therapy and callous-unemotional traits: effects of a pilot study examining modified behavioral contingencies on child behavior. Behav Ther 45:606-618

32. Moffitt TE, Arseneault L, Jaffee SR, Kim-Cohen J, Koenen KC, Odgers CL, Slutske WS, Viding E (2008) Research review: DSM-V conduct disorder: research needs for an evidence base. $\mathrm{J}$ Child Psychol Psychiatry 49:3-33

33. O'Nions E, Sebastian CL, McCrory E, Chantiluke K, Happe F, Viding E (2014) Neural bases of theory of mind in children with autism spectrum disorders and children with conduct problems and callous-unemotional traits. Dev Sci 17:786-796

34. Pardini D, Stepp S, Hipwell A, Stouthamer-Loeber M, Loeber R (2012) The clinical utility of the proposed DSM-5 callous-unemotional subtype of conduct disorder in young girls. J Am Acad Child Adolesc Psychiatry 51:62-73

35. Pardini DA, Loeber R (2007) Interpersonal and affective features of psychopathy in children and adolescents: advancing a developmental perspective. Introduction to special section. J Clin Child Adolesc Psychol 36:269-275

36. Ravens-Sieberer U, Gosch A, Rajmil L, Erhart M, Bruil J, Duer W, Auquier P, Power M, Abel T, Czemy L, Mazur J, Czimbalmos
A, Tountas Y, Hagquist C, Kilroe J (2005) KIDSCREEN-52 quality-of-life measure for children and adolescents. Expert Rev Pharmacoecon Outcomes Res 5:353-364

37. Ravens-Sieberer U, group tEK (2006) The KIDSCREEN questionnaires: quality of life questionnaires for children and adolescents-Handbook. Pabst Science Publishers, Lengerich

38. Rogers J, Viding E, Blair RJ, Frith U, Happé F (2006) Autism spectrum disorder and psychopathy: shared cognitive underpinnings or double hit? Psychol Med 36:1789-1798

39. Roose A, Bijttebier P, Decoene S, Claes L, Frick PJ (2010) Assessing the affective features of psychopathy in adolescence: a further validation of the inventory of callous and unemotional traits. Assessment 17:44-57

40. Rowe R, Maughan B, Moran P, Ford T, Briskman J, Goodman R (2010) The role of callous and unemotional traits in the diagnosis of conduct disorder. J Child Psychol Psychiatry 51:688-695

41. Schwenck C, Mergenthaler J, Keller K, Zech J, Salehi S, Taurines R, Romanos M, Schecklmann M, Schneider W, Warnke A, Freitag CM (2012) Empathy in children with autism and conduct disorder: group-specific profiles and developmental aspects. J Child Psychol Psychiatry 53:651-659

42. Waschbusch DA, Carrey NJ, Willoughby MT, King S, Andrade BF (2007) Effects of methylphenidate and behavior modification on the social and academic behavior of children with disruptive behavior disorders: the moderating role of callous/unemotional traits. J Clin Child Adolesc Psychol 36:629-644

43. Waschbusch DA, Porter S, Carrey N, Kazmi SO, Roach KA (2004) Investigation of the heterogeneity of disruptive behaviour in elementary-age children. Can J Behav Sci 36:97-112

44. Waschbusch DA, Willoughby MT (2008) Attention-deficit/ hyperactivity disorder and callous-unemotional traits as moderators of conduct problems when examining impairment and aggression in elementary school children. Aggress Behav 34:139-153

45. Wechsler D (1991) Manual for the Wechsler intelligence scale for children-Third edition (WISC-III). The Psychological Corporation, San Antonio

46. Weitkamp K, Daniels JK, Romer G, Wiegand-Grefe S (2013) Health-related quality of life of children and adolescents with mental disorders. Health Qual Life Outcomes 11:129 